INFECTION

CONTIROI

\section{Of Roman Gods and a New Journal}

The Roman deity, Janus, guardian of the doors and gates of heaven, presided over the entrance upon, or beginning of, all things. In that special duty, he is portrayed with one face on the front and another on the back of his head, representing simultaneous vigils over past and future events. It seems appropriate to recall Janus in 1980 not only as we enter a new year and a new decade but also as we introduce a scientific journal that focuses on hospital epidemiology and all aspects of infection control.

The modern era of hospital infection control is short, originating only 20 years ago in Great Britain with the employment of an infection control sister. ${ }^{1,2}$ The concept survived the Atlantic crossing, and in 1970 the first International Conference on Nosocomial Infections was held in Atlanta. ${ }^{3}$ That meeting was followed by the formation of an Association for Practitioners of Infection Control (APIC) in 1972. Since then, heightened interest in hospital epidemiology and infection control has been evidenced by national meetings of physician epidemiologists at the ICAAC conferences in 1978 and 1979, circulation of a popular newsletter, * recent publication of books related to infection control, ${ }^{4-8}$ and introduction of three journals on infection control in 1980 . $†$ Thus, with respect to the developments of a commitment to the field and of a formal literature, we are indeed at the end of the beginning.

The purpose of INFECTION CONTROL is to present scientifically sound primary investigations, reviews, and articles in related areas, such as trends in medicolegal decisions, assessments of vaccine use, and patterns of antimicrobial resistance. Although its principal focus will be on nosocomial infections, INFECTION CONTROL also encourages contributions dealing with issues similar to those mentioned in communities around the globe. The journal is directed broadly to those interested in the investigation and prevention of infections-physicians, practitioners, epidemiologists, and microbiologists in both academic and community settings in all countries. In this respect the task of the editors is to insure that clarity of thought is conveyed through simplicity of language.

Several steps have been taken to ensure the success of

*Hospital Infection Control, published by American Health Consultants Inc., Atlanta.

tIn addition to INFECTION CONTROL, there are The Joumal of Hospital Infection, London, Academic Press, and The American Journal of Infection Control, St. Louis, CV Mosby. this new venture. The publishers have a respected. reputation in medical publishing and are committed to quality and to science. The editorial board is strong, energetic, and broadly experienced in various medical disciplines.

Although the control of infections is inherently a multi-disciplinary field, it has been difficult during these early years to provide a common forum for the exchange of ideas. Our present knowledge is limited and our working assumption is that by rigorously addressing basic questions we may find truth. It is hoped that these pages will provide a vehicle for the testing of ideas and the emergence of new insights with practical applications. As such, INFECTION CONTROL will support the needs of members of various learned societies, including the Infectious Diseases Society of America, APIC, American Society of Microbiology, American Society of Clinical Pathologists, and the Society for Epidemiologic Research, as well as similar scholarly organizations abroad.

With these goals in mind, we launch a new journal in 1980 in the month dedicated to the memory of Janus. It is customary as we enter a new year and a new decade to review our aspirations, having taken stock of recent efforts. In introducing INFECTION CONTROL we are mindful of the past, yet look forward to new challenges, new adventures, new friends, and new successes. We welcome your participation.

\section{REFERENCES}

1. Moore B. Control of Infection. The employment of a senior member of the nursing staff as a member of the control of infection team in general hospitals. Report to the South Western Regional Hospital Board, 1961.

2. Moore B. The infection control sister in British hospitals. Inf Nurs Rev 17:84-92, 1970.

3. Proceedings of the International Conference on Nosocomial Infections. Center for Disease Control. August 3-6, 1970. Baltimore; Waverly Press, 1971.

4. Infection Control in Health Care Facilities: Microbiological Surveillance. Cundy KR, Ball W (eds). Baltimore, University Park Press, 1977.

5. Occurrence, Diagnosis and Sources of Hospital Associated Infections. Fahlber WJ, Groschell D (eds). New York, Marcel Dekker, 1978.

6. Epidemiology for the Infection Control Nurse. Barrett-Connor E; Brandt SL, Simon HJ, et al. (eds). St. Louis, CV Mosby, 1978.

7. Problems in the General Hospital Population and Specifia Measures of Control. Groschel D (ed). New York, Marcel Dekker, 1979.

8. Hospital Infections. Bennet JV, Brachman PS (eds). Boston, Little, Brown and Co., 1979

\section{RICHARD P. WENZEL}

\section{WILliaM A. SCHAFFNER}




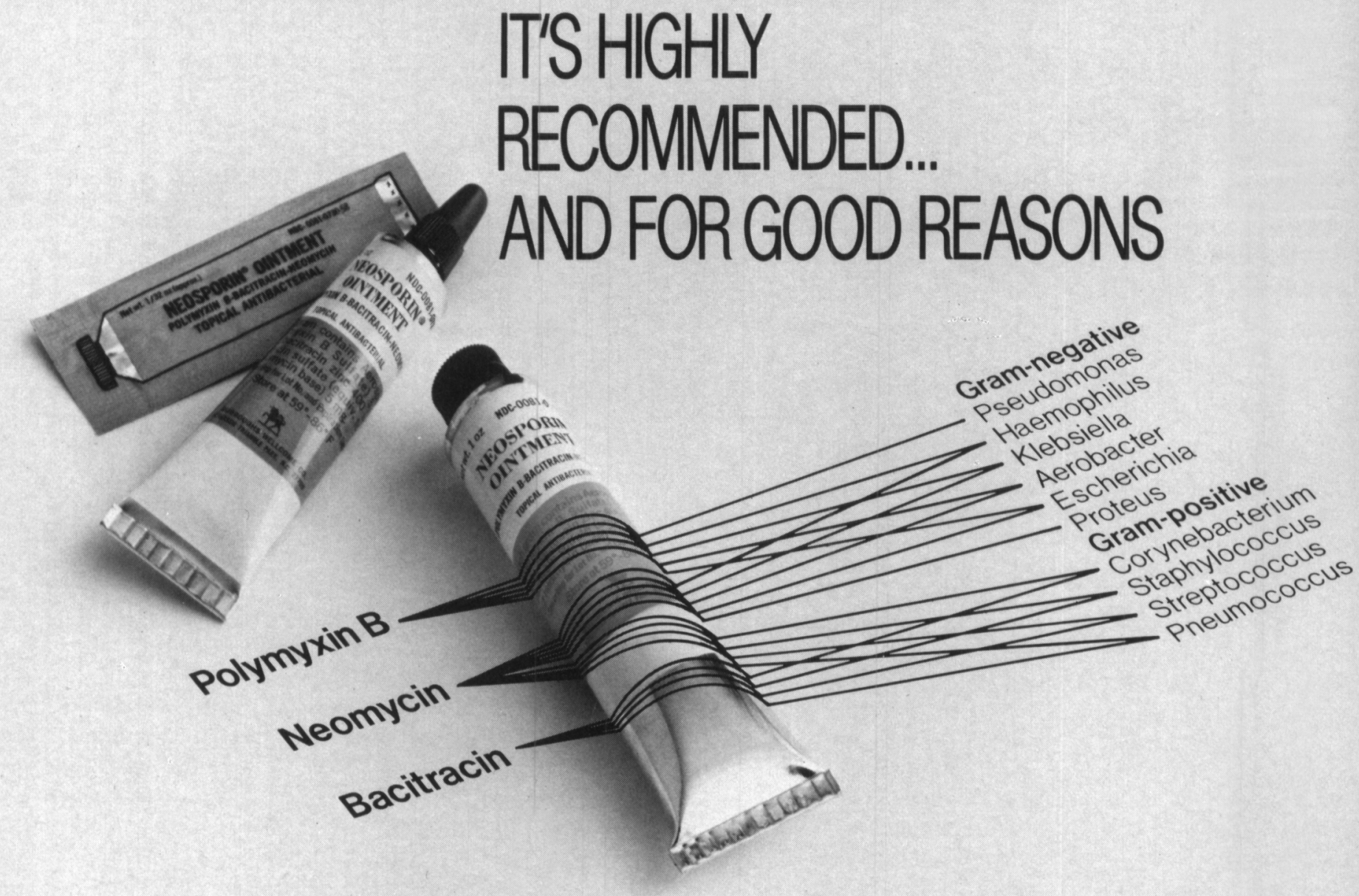

1. provides broad-spectrum, overlapping antibacterial effectiveness against common susceptible pathogens, including staph and strep

2. helps prevent topical infections, and treats those that have already started

3. it's good medicine for abrasions, lacerations, open wounds, primary pyodermas, secondarily infected dermatoses; and it's painless and cosmetically pleasing

4. contains three antibiotics that are rarely used systemically

5. you can recommend it in any of the three convenient package sizes: 1 oz tube, $1 / 2$ oz tube, or the versatile, single-use foil packet

\section{NEOSPORIN'Ointment}

\section{nst}

(polymyxin B-bacitracin-neomycin)

Each gram contains: Aerosporin ${ }^{\star}$ (Polymyxin B Sulfate) 5,000 units, bacitracin zinc 400 units, neomycin sulfate $5 \mathrm{mg}$ (equivalent to $3.5 \mathrm{mg}$ neomycin base); special white petrolatum qs; in tubes of $1 \mathrm{oz}$ and $1 / 2 \mathrm{oz}$ and $1 / 32 \mathrm{oz}$ (approx.) foil packets.

WARNING: Because of the potential hazard of nephrotoxicity and ototoxicity due to neomycin, care should be exercised when using this product in treating extensive burns, trophic ulceration and other extensive conditions where absorption of neomycin is possible. In burns where more than 20 percent of the body surface is affected, especially if the patient has impaired renal function or is receiving other aminoglycoside antibiotics concurrently, not more than one application a day is recommended.
When using neomycin-containing products to control secondary infection in the chronic dermatoses, it should be borne in mind that the skin is more liable to become sensitized to many substances, including neomycin. The manifestation of sensitization to neomycin is usually a low grade reddening with swelling, dry scaling and itching; it may be manifest simply as a failure to heal. During longterm use of neomycin-containing products, periodic examination for such signs is advisable and the patient should be told to discontinue the product if they are observed. These symptoms regress quickly on withdrawing the medication. Neomycin-containing applications should be avoided for that patient thereafter

PRECAUTIONS: As with other antibacterial preparations, prolonged use may result in overgrowth of nonsusceptible organisms, including fungi. Appropriate measures should be taken if this occurs.

ADVERSE REACTIONS: Neomycin is a not uncommon cutaneous sensitizer. Articles in the current literature indicate an increase in the prevalence of persons allergic to neomycin. Ototoxicity and nephrotoxicity have been reported (see Warning section).

Complete literature available on request from Professional Services Dept. PML.

andiacterial preparati 